Rev. Bras. Saúde Prod. Anim., Salvador, v.13, n.3, p.755-774 jul./set., 2012 http://www.rbspa.ufba.br ISSN 15199940

\title{
Novos conceitos em nutrição de aves ${ }^{1}$
}

\author{
New concepts in poultry nutrition
}

\author{
PESSÔA, Gabriel Borges Sandt'; TAVERNARI, Fernando de Castro ${ }^{3}$; VIEIRA \\ Rodolfo Alves ${ }^{2}$, ALBINO; Luiz Fernando Texeira ${ }^{2 *}$
}

\author{
${ }^{1}$ Revisão apresentada no Congresso Brasileiro de Zootecnia (ZOOTEC 2011). \\ ${ }^{2}$ Universidade Federal de Viçosa, Centro de Ciências Agrárias, Departamento de Zootecnia, Viçosa, \\ Minas Gerais, Brasil. \\ ${ }^{3}$ Embrapa Suínos e Aves, Concórdia, Santa Catarina, Brasil. \\ *Endereço para correspondência: lalbino@ufv.br
}

\section{RESUMO}

A grande evolução da avicultura brasileira e o consequente aumento da produção de resíduos, bem como as exigências impostas pela União Europeia, quanto ao controle da excreção de poluentes, resultam na busca de novos conceitos relativos à nutrição animal. Dentre esses conceitos, destaca-se o uso da proteína ideal, da injeção de nutrientes in ovo, da alimentação dos animais em fases e a suplementação de aditivos como prebióticos, probióticos, enzimas, extratos herbais e minerais orgânicos nas dietas das aves. Várias pesquisas têm sido feitas a fim de comprovar a eficiência dessas práticas de nutrição e muitas delas concluem que a aplicação de estratégias nutricionais tem um significativo potencial de redução da excreção de nutrientes pelos frangos de corte, além de terem ainda, a vantagem de reduzir os custos de produção.

Palavras-chave: avicultura, estratégias, nutrição.

\section{SUMMARY}

The great evolution of the Brazilian poultry industry, the consequent increased production of waste and the requirements imposed by the European Union concerning the control of the excretion of pollutants result in the search for new concepts of animal nutrition. Among these concepts, we can mention the use of ideal protein, the injection of nutrients in the egg, the animal nutrition based on phases and supplementation of additives such as prebiotics, probiotics, enzymes, herbal extracts and organic minerals in the diets of birds. Several studies have been conducted to prove the effectiveness of these practices of nutrition and many of them conclude that the application of nutritional strategies have significant potential to reduce nutrient excretion by broiler chickens, and have also the advantage of reducing the production costs.

Keywords: nutrition, poultry, strategy.

\section{INTRODUÇÃO}

O Brasil tem se destacado mundialmente pela sua forte produção no setor agropecuário e, no bojo do agronegócio, o ramo da avicultura foi o mais evoluído nos últimos anos. Hoje, o País se encontra na posição de terceiro maior produtor de carne de frango no mundo e o maior exportador. $\mathrm{O}$ crescimento na produção de aves do Brasil tem sido constante, e isso pode ser comprovado já no limiar deste ano, com um aumento de $8,76 \%$ na produção de janeiro, em relação ao mesmo período do ano passado (AVISITE, 2011). Dentre as áreas responsáveis por esse avanço, destaca-se o melhoramento 
genético, a nutrição, as técnicas de manejo e a sanidade. Qualquer falha em uma dessas áreas pode afetar o desempenho das aves e, consequentemente, aumentar o custo de produção.

Todavia, junto com o aumento da produção de carne vem o aumento dos resíduos, o que tem gerado elevada preocupação devido à excreção excessiva pelas aves de nitrogênio $(\mathrm{N})$, de fósforo (P) e de microminerais sobre o meio ambiente. Isso levou a comunidade Europeia a implantar, no ano 2000, o Conselho Diretivo 96/61/EC, que regulamenta o controle integrado de prevenção e controle da poluição ambiental. A partir desse conselho, as grandes integrações de aves e suínos só podem emitir poluentes na água e no solo, inclusive nitratos, e no ar, sobretudo, amônia, dentro de um limite. Assim. a nutrição, no sentido de atender os requerimentos nutricionais dos animais e, ainda, diminuir a emissão de nutrientes no meio ambiente tem apresentado avanços ao longo dos anos.

\section{PROGRAMAS DE ALIMENTAÇÃO}

Em geral, os frangos recebem diferentes rações de acordo com a idade, fato importante, pois durante o crescimento das aves ocorrem alterações nas suas exigências nutricionais. Um conjunto de rações fornecido a um lote de frangos é conhecido como programa de alimentação.

No Brasil, são utilizados principalmente os programas de três fases (inicial, crescimento e terminação), de quatro fases (inclusão de uma ração pré-inicial) e ainda o programa de cinco fases, com uma pré-inicial e duas de crescimento. Existe a possibilidade do uso de programas de alimentação múltiplos (phase-feeding), nos quais um grande número de dietas é fornecido às aves durante sua criação, porém, vale ressaltar que a divisão em muitas fases pode se tornar inviável economicamente, devido ao maior trabalho.

Os níveis nutricionais utilizados em cada fase representam o valor médio da exigência para a fase avaliada, o que significa que no princípio da fase as aves recebem dieta com nível subótimo do nutriente e, no final, o recebem em excesso (Figuras 1a e 1b). A divisão do período de criação em um número maior de fases, ou seja, o uso de maior número de dietas, ajusta melhor o exigido pela ave com o fornecido pela ração. Assim, pesquisas foram feitas a partir do programa de arrazoamento múltiplo, com troca da ração a cada dois ou sete dias para frangos de corte em diferentes períodos. Os autores concluem que estes não prejudicam o desempenho, nem a qualidade de carcaça das aves, mas permitem uma redução significativa do custo com a alimentação (WARREN \& EMMERT, 2000).

Vários autores, como Lana et al. (2001) e Pope et al. (2002), demonstraram que o aumento do número de rações (fases) não influenciou o desempenho $\mathrm{e} o$ rendimento de carcaça de frangos de corte, entretanto, o procedimento reduziu o custo de produção. Shiroma et al. (1996) concluíram que frangos de corte alimentados com os programas de $3 ; 4$ e 5 rações não apresentam diferenças no ganho de peso e conversão alimentar, mas os programas de 4 e 5 rações reduziram o custo/kg de peso vivo em 2,7\% em relação ao programa de 3 fases.

Experimentos foram realizados nas condições brasileiras por Buteri et al. (2009) com o objetivo de avaliar os efeitos de diferentes planos nutricionais sobre o desempenho produtivo $\mathrm{e}$ 
econômico de frangos de corte. Os planos nutricionais estudados foram os de $3 ; 5$ e 28 rações. O plano de 28 rações era preparado a partir de uma dieta para o primeiro dia e diluída proporcionalmente a cada dois dias, com uma dieta para o dia 56.

Com base nos dados referentes ao desempenho, o autor concluiu que os programas de alimentação de 28 rações testados são equivalentes entre si e permitem igual desempenho, quando comparados aos programas de 3 e 5 rações. $\mathrm{Na}$ análise econômica para frangos de corte aos 42 e 56 dias de idade, os maiores índices de rentabilidade foram obtidos com o uso do plano de alimentação de 28 rações.

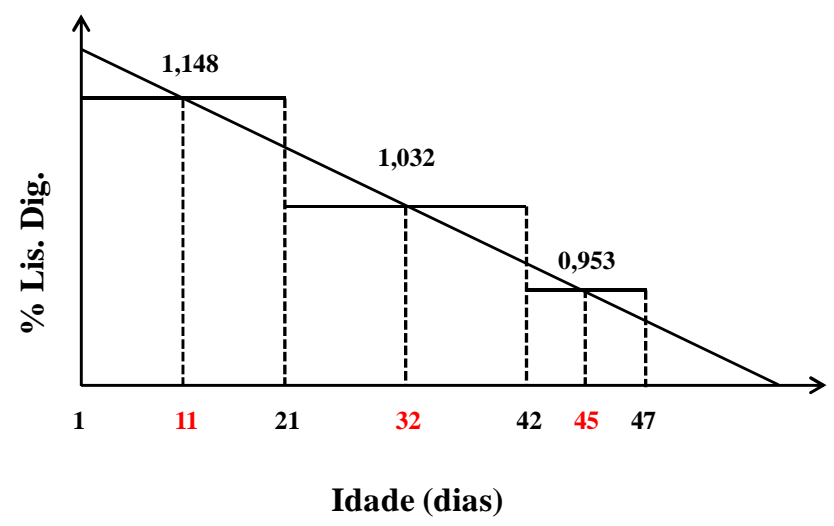

Figura 1a. Relação entre os níveis de exigência e fornecimento de lisina em um plano de alimentação com três fases (BUTERI, 2003)

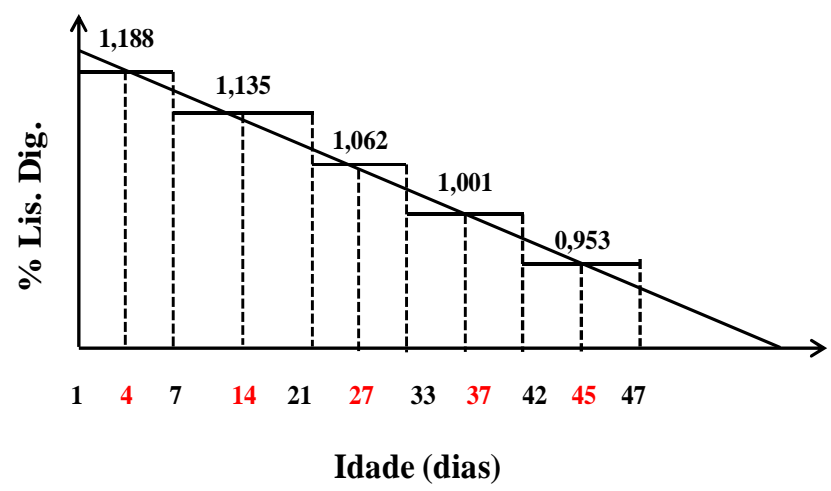

Figura 1b. Relação entre os níveis de exigência e fornecimento de lisina em um plano de alimentação com cinco fases (BUTERI, 2003)

\section{NUTRIÇÃO IN OVO}

Graças ao grande desenvolvimento genético que vem ocorrendo nas linhagens avícolas, destinadas à produção de carne, a idade recomendada ao abate do frango está consideravelmente menor. Por isso, o período de incubação se torna cada vez 
mais importante, de modo que já representa cerca de $35 \%$ do período de vida do animal. Assim, a limitação no desenvolvimento neonatal pode implicar um baixo desempenho do frango.

O acesso do embrião a nutrientes pode melhorar o desenvolvimento do sistema digestório (FOYE et al., 2005), a eclodibilidade e o desempenho da ave. Com base nessas premissas, o conceito da suplementação de nutrientes na fase préeclosão, ou nutrição in ovo, foi estabelecido com a finalidade de aumentar o estado nutricional do embrião, além de permitir o contato de nutrientes com a mucosa intestinal antes mesmo da eclosão, o que melhora a capacidade de digestão do embrião.

A inoculação in ovo deve ser realizada por volta do $17^{\circ}$ dia, quando $\mathrm{O}$ embrião começa a ingerir oralmente o líquido amniótico e, consequentemente, as substâncias presentes também são ingeridas. Além disso, tem-se demonstrado que o embrião possui enzimas digestivas que tornam possível a alimentação na fase pré-eclosão. Apesar desses dados, essa técnica é recente e pouco se sabe acerca dos níveis e tipos de nutrientes que podem ser utilizados na nutrição do embrião.
Um estudo que pode indicar quais nutrientes usar é o da composição do saco vitelino. $O$ saco vitelino é a fonte primária de nutrição do pinto (BURNHAM et al., 2001) e, segundo Ladgary et al. (2010), a gema de ovos frescos provenientes de matrizes com 50 semanas de idade contém, aproximadamente, $15,62 \%$ de proteína, $27,32 \%$ de lipídios, $0,42 \%$ de carboidratos, $53,32 \%$ de água e 3,32\% de outros.

Pesquisas desenvolvidas na Universidade Federal de Viçosa avaliaram o efeito da inoculação de $0,5 \mathrm{ml}$ de solução salina (controle positivo), de solução nutritiva de carboidratos (glicose + sacarose), de 12 vitaminas e de minerais quelatados (zinco, manganês e cobre) em embriões com 17,5 dias de incubação, sobre o desempenho e o desenvolvimento do sistema imune de pintos de corte. Pintos provenientes de ovos inoculados, com solução de $2,5 \%$ glicose $+3 \%$ sacarose, apresentaram melhores resultados para ganho de peso, conversão alimentar e rendimento de peito aos 21 dias de idade. A melhora foi da ordem de $4,4 \%$ e $5,4 \%$ no ganho de peso e no peso do filé de peito, respectivamente, quando comparado ao grupo controle (Tabela 1).

Tabela 1. Efeito da inoculação de soluções nutritivas in ovo sobre o ganho de peso (GP), conversão alimentar (CA) e rendimento de filé de peito de frangos aos 21 dias de idade

\begin{tabular}{lcccc}
\hline \multirow{2}{*}{${\text { Inoculação } \text { in ovo }^{1}}$} & \multicolumn{2}{c}{ Desempenho } & \multicolumn{2}{c}{ Filé de Peito } \\
\cline { 2 - 5 } & $\mathrm{GP}(\mathrm{g})$ & $\mathrm{CA}$ & $\mathrm{g} / \mathrm{ave}$ & $\%$ do PV \\
\hline Controle (-) & $673,5^{\mathrm{b}}$ & $1,53^{\mathrm{a}}$ & $110,6^{\mathrm{b}}$ & $15,22^{\mathrm{b}}$ \\
Solução salina $(0,5 \%)$ & $682,6^{\mathrm{ab}}$ & $1,54^{\mathrm{a}}$ & $110,1^{\mathrm{b}}$ & $15,10^{\mathrm{b}}$ \\
Glic. $(2,0 \%)+$ Sac. $(2,0 \%)$ & $690,5^{\mathrm{ab}}$ & $1,46^{\mathrm{b}}$ & $111,7^{\mathrm{b}}$ & $15,15^{\mathrm{b}}$ \\
Glic. $(2,5 \%)+$ Sac. $(3,0 \%)$ & $702,9^{\mathrm{a}}$ & $1,44^{\mathrm{b}}$ & $116,6^{\mathrm{a}}$ & $15,62^{\mathrm{a}}$ \\
Solução de Vitaminas & $691,9^{\mathrm{ab}}$ & $1,49^{\mathrm{a}}$ & $113,1^{\mathrm{ab}}$ & $15,30^{\mathrm{b}}$ \\
Solução Minerais quelatados & $690,3^{\mathrm{ab}}$ & $1,50^{\mathrm{a}}$ & $112,0^{\mathrm{b}}$ & $15,20^{\mathrm{b}}$ \\
\hline CV $(\%)$ & 3,2 & 5,9 & 4,5 & 2,7 \\
\hline
\end{tabular}

Adaptado de Campos (2007).

${ }^{1}$ Injeção in ovo aos 17,5 dias da incubação. 
A inoculação de açúcares no fluido amniótico, antes da eclosão, pode aumentar a energia disponível para o embrião, de maneira a elevar a reserva de glicogênio e, por outro lado, diminuir o uso das proteínas musculares, o que contribui para melhor desempenho da ave. Esses carboidratos elevam as atividades das enzimas produzidas no intestino (TAKO et al., 2004) e aumentam a capacidade de digestão e de absorção dos nutrientes que, por sua vez, é reduzida na fase final do desenvolvimento embrionário.

A administração de nutrientes in ovo pode ter efeito positivo sobre a concentração de glicogênio no embrião, sobre o desenvolvimento do intestino e sobre a capacidade de digestão, de forma a reduzir a mortalidade pós-eclosão, bem como diminuir a gliconeogênese a partir de proteínas corporais e, consequentemente, aumentar o desenvolvimento muscular e o rendimento de peito.

Uni et al. (2005) avaliaram os efeitos da inoculação in ovo de soluções compostas de carboidratos altamente digestíveis e $\beta$-hidroxi- $\beta$-metilbutirato (HMB), sobre o peso corporal e do peito de aves até 25 dias de idade. Em todos os parâmetros analisados, os resultados com a inoculação in ovo foram melhores que o do tratamento controle (Tabela 2).

Tabela 2. Efeito da inoculação de soluções nutritivas in ovo sobre o desempenho e o rendimento de peito de frangos aos 10 e 25 dias de idade

\begin{tabular}{lcccc}
\hline \multirow{2}{*}{ Parâmetro } & \multicolumn{2}{c}{10 dias } & \multicolumn{2}{c}{25 dias } \\
\cline { 2 - 5 } & Controle & in ovo & Controle & in ovo \\
\hline Peso vivo $(\mathrm{g})$ & 243,0 & 254,0 & 943,0 & 997,0 \\
Peso do peito $(\mathrm{g})$ & 27,9 & 30,3 & 114,0 & 130,0 \\
Rendimento de peito $(\%)$ & 11,4 & 12,3 & 12,0 & 13,0 \\
\hline
\end{tabular}

Adaptado de Uni et al. (2005).

\section{DIETA PRÉ-ALOJAMENTO}

Sabe-se que um dos principais problemas que afetam a qualidade dos pintos é o tempo em que eles ficam nas caixas de transporte até chegarem às granjas. Assim, quanto mais cedo for oferecida uma ração a estes, menor será sua desidratação, isto é, ocorrerá possivelmente maior estímulo ao desenvolvimento da mucosa e a consequente perda de peso será reduzida. Noy \& Sklan (2000) verificaram que pintos sujeitos a jejum de 48 horas, após a eclosão, tiveram diminuição no peso corporal. Todavia, durante as 48 horas, o peso do intestino delgado aumentou $60 \%$ nos animais desprovidos de alimento e $200 \%$ naqueles providos de alimentos. Ao observar as diferentes porções do intestino, atesta-se que a maior velocidade de crescimento relativo da área e da altura das vilosidades intestinais se estabilizam aos 6 - 8 dias no duodeno e com 10 dias no jejuno e íleo (Noy \& Sklan, 1998).

Nery et al. (2006), ao avaliarem o fornecimento de diferentes dietas préalojamento sobre o desempenho de frangos de corte até os 42 dias de idade, concluíram que a utilização da dieta pré-alojamento minimizou os efeitos 
negativos ocasionados pelo jejum, durante o transporte (Tabela 3).

A partir dos conceitos nutricionais para formulação de dietas específicas reservada a frangos de corte, na fase pós-eclosão e pré-inicial, o nutricionista poderá demonstrar, por intermédio de avaliações zooeconômicas, a eficiência no investimento de dietas pós-eclosão ou pré-iniciais de alto valor biológico.

Tabela 3. Efeito da alimentação pré-alojamento sobre ganho de peso (GP), conversão alimentar (CA) e consumo de ração (CR) de frangos de corte às 36 horas 7 , 21 e 42 dias de idade

\begin{tabular}{lccccc}
\hline \multirow{2}{*}{ Tratamento } & \multicolumn{2}{c}{36 horas } & \multicolumn{2}{c}{42 dias } \\
\cline { 2 - 6 } & $\Delta$ peso $^{1}$ & GP $^{2}$ & CA & GP $^{2}$ & CA \\
\hline T1 - Alojamento rápido & $10,8^{\mathrm{a}}$ & $113^{\mathrm{a}}$ & $1,610^{\mathrm{a}}$ & $2288^{\mathrm{a}}$ & 1,770 \\
T2 - Jejum 36 h & $-4,5^{\mathrm{b}}$ & $89^{\mathrm{c}}$ & $1,540^{\mathrm{ab}}$ & $2189^{\mathrm{cd}}$ & 1,725 \\
T3 - Dieta pré-alojamento (DP) & $-3,7^{\mathrm{b}}$ & $97^{\mathrm{b}} \mathrm{c}$ & $1,490^{\mathrm{ab}}$ & $2226^{\mathrm{bc}}$ & 1,754 \\
T4 - DP + Glutamina & $-3,4^{\mathrm{b}}$ & $100^{\mathrm{b}}$ & $1,450^{\mathrm{b}}$ & $2266^{\mathrm{ab}}$ & 1,756 \\
\hline ANOVA & 0,001 & 0,001 & 0,001 & 0,001 & 0,372 \\
\hline CV $(\%)$ & 3,47 & 3,99 & 5,63 & 1,78 & 2,88 \\
\hline
\end{tabular}

Adaptado de Nery et al. (2006).

${ }^{1} \Delta$ peso $=$ variação do peso, em gramas; ${ }^{2}$ valores expressos em gramas.

\section{PROTEÍNA IDEAL}

De acordo com Emmert \& Baker (1997) a proteína ideal pode ser definida como o balanceamento exato dos aminoácidos, sem deficiências, nem sobras, cujo objetivo é satisfazer as exigências absolutas de todos os aminoácidos para mantença e para ganho máximo de proteína corporal, o que reduz o uso de aminoácidos como fonte de energia e diminui a excreção de nitrogênio. Sabese que apenas $45 \%$ do $\mathrm{N}$ consumido pelas aves são retidos como proteína animal, logo, $55 \%$ do $\mathrm{N}$ ingerido são excretados, o que contribui para aumentar a poluição ambiental (CAUWENBERGHE \& BURNHAM, 2001). Já Ferket (2002) considera que somente $35 \%$ do $\mathrm{N}$ são retidos pelo animal.

Porém, o uso do conceito de proteína ideal só é possível porque os principais aminoácidos limitantes (lisina, metionina, treonina, triptofano e valina) estão comercialmente disponíveis e a cada ano se tornam mais competitivos com relação aos custos dos aminoácidos presentes nos alimentos. A lisina, embora seja o segundo aminoácido limitante para aves, foi estabelecida como referência (padrão $=100 \%$ ) para as exigências dos outros aminoácidos essenciais (Tabela 4), por possuir as seguintes características: é um aminoácido estritamente essencial, sem nenhuma via de síntese endógena; possui metabolismo orientado principalmente para deposição de proteína corporal; a sua análise nos alimentos está em contínuo avanço, e muita informação existe sobre sua concentração e digestibilidade nos alimentos. Existe ainda grande quantidade de pesquisas e informações sobre os requisitos de lisina para aves, frente a uma variedade de dietas, condições ambientais e composição corporal. 
Rev. Bras. Saúde Prod. Anim., Salvador, v.13, n.3, p.755-774 jul./set., 2012 http://www.rbspa.ufba.br ISSN 15199940

Tabela 4. Relação de alguns aminoácidos com a lisina para estimar as exigências de aminoácidos de frangos de corte

\begin{tabular}{lccc}
\hline \multicolumn{1}{c}{ Aminoácido } & $\begin{array}{c}\text { Geraert }(2005)^{1} \\
1994-1999\end{array}$ & $\begin{array}{c}\text { UFV }(2005)^{2} \\
\text { Inicial / Cresc. }\end{array}$ & $\begin{array}{c}\text { UFV }(2011)^{3} \\
\text { Inicial / Cresc. }\end{array}$ \\
\hline Lisina (\%) & 100 & $100 / 100$ & $100 / 100$ \\
Met. + Cis. (\%) & 74 & $71 / 72$ & $72 / 73$ \\
Treonina (\%) & 68 & $65 / 65$ & $65 / 65$ \\
Triptofano (\%) & 17 & $16 / 17$ & $17 / 18$ \\
Arginina (\%) & 116 & $105 / 105$ & $108 / 108$ \\
Valina (\%) & 80 & $75 / 77$ & $77 / 78$ \\
Isoleucina (\%) & 69 & $65 / 67$ & $67 / 68$ \\
Gli + Ser Total (\%) & - & $150 / 140$ & $147 / 134$ \\
\hline
\end{tabular}

${ }^{\mathrm{T}}$ Média das publicações entre 1994 e 1999 de cinco autores, citados por Geraert et al. (2005); ${ }^{2}$ Valores de Rostagno et al. (2005); ${ }^{3}$ Valores de Rostagno et al. (2011).

Borges et al. (2003) avaliaram a utilização de ingredientes alternativos para frangos, em rações formuladas com base no conceito de proteína ideal. Os autores observaram que a formulação de ração com aminoácidos digestíveis resultou em maior ganho de peso e melhor conversão alimentar de 1 a 7 , bem como de 1 a 21 dias de idade.

O nível de proteína bruta das rações pode ser reduzido pela substituição do farelo de soja por aminoácidos sintéticos, sem afetar negativamente o desempenho animal. Entretanto, existem poucas informações disponíveis sobre quais aminoácidos, além dos normalmente suplementados, passam a ser limitantes em rações que possuem baixo nível proteico. A partir desse ponto, foram realizados experimentos com frangos de corte (ROSTAGNO et al., 2002ab), no intuito de avaliar rações com baixos níveis de proteína com a adição de aminoácidos e a retirada individual dos aminoácidos glicina, ácido glutâmico, isoleucina e valina. Os resultados (Tabela 5) mostram que rações com 19 e com $18 \%$ de proteína, para pintos de 8 a 21 dias de idade, são deficientes em glicina+serina. Entretanto, para o período de 22 a 40 dias, pode-se observar que as aves alimentadas com rações compostas de $17 \%$ de proteína, sem a suplementação de isoleucina e de valina, apresentaram menor ganho de peso.

Tabela 5. Efeito do nível de proteína e da retirada de aminoácidos sobre o ganho de peso $(\mathrm{g})$ em frangos de corte $\operatorname{machos}^{1}$

\begin{tabular}{lcc}
\hline Fase Experimental, dias & $8-21$ dias & $22-42$ dias \\
\hline Tratamento/Nível de Proteína (\%) & $19 / 18$ & 17 \\
\hline Com aminoácidos (Gli, Glu, Iso, Val) & $734^{\mathrm{a}}$ & $1629^{\mathrm{a}}$ \\
Sem glicina & $714^{\mathrm{b}}$ & $1608^{\mathrm{a}}$ \\
Sem ácido glutâmico & $730^{\mathrm{a}}$ & $1605^{\mathrm{a}}$ \\
Sem isoleucina & $734^{\mathrm{a}}$ & $1590^{\mathrm{b}}$ \\
Sem valina & $732^{\mathrm{a}}$ & $1590^{\mathrm{b}}$ \\
Sem aminoácidos (Gli, Glu, Iso, Val) & $700^{\mathrm{b}}$ & $1593^{\mathrm{b}}$ \\
\hline Controle (Proteína) & $721(22 \%)$ & $1638(20 \%)$ \\
\hline
\end{tabular}

Adaptado de Rostagno et al. (2002ab).

${ }^{1}$ Rações com níveis adequados de Met+Cis, Lis, Tre, Tri e Arg. 
Tais resultados sugerem que, na fase inicial, o nível de glicina+serina deve ser controlado e, na fase de crescimento/final, deve-se levar em consideração os níveis dos aminoácidos isoleucina e leucina. A recomendação atual, para aplicação do conceito de proteína ideal em formulações de rações, seria a redução do nível proteico da ração, o que provoca a eliminação da sobra de aminoácidos essenciais e não essenciais. Quando necessário, devem ser suplementados aminoácidos industriais, como metionina, lisina e treonina para evitar deficiências (ROSTAGNO et al., 2003a).

\section{ADITIVOS}

Embora produzidos desde a década de 70 pelas indústrias brasileiras, a utilização dos minerais quelatados na nutrição animal é recente e a discussão de sua importância está baseada em suas ações específicas a nível celular e sua maior biodisponibilidade em relação aos minerais inorgânicos. São denominados quelatos os compostos formados por íons metálicos, sequestrados por substâncias orgânicas como aminoácidos, peptídeos ou complexos polissacarídeos que proporcionam a esses íons alta disponibilidade biológica, alta estabilidade e solubilidade (KIEFER, 2005).

Os microminerais orgânicos disponíveis atualmente no mercado possuem diferentes características químicas e físicas, em decorrência do tipo de ligante utilizado e, consequentemente, geram diferentes respostas nutricionais. Deve-se levar em consideração que nem todos minerais orgânicos são capazes de aumentar a biodisponibilidade de um mineral da mesma maneira (CAO et al., 2000). De acordo com a Association of
American Feed Control Officials (AAFCO, 1999), existem cinco categorias de microminerais orgânicos, a saber: Complexo Metal Aminoácido específico (resultante da complexação de um sal de metal solúvel com um aminoácido específico, geralmente, refere-se a uma molécula de aminoácido ligada a um íon metal. Essa ligação é mais consistente que quelatos, proteinados e polissacarídeos, na qual a maioria desses produtos é composta por microminerais aleatoriamente ligados a dipeptídeos, tripeptídeos ou fragmentos de proteínas. O complexo metal aminoácido específico é bem definido e muito consistente em sua produção. Exemplos: Zinco-Metionina, Manganês-Metionina, Cobre-Lisina e Ferro-Metionina); Complexo Metal Aminoácido (muito semelhante ao complexo metal aminoácido específico, é resultante da complexação de um sal de metal com uma mistura de aminoácidos livres. A única diferença entre as duas categorias é que o aminoácido não é especificado); Quelato Metal Aminoácido (resultante da reação de um íon metálico de um sal solúvel com aminoácidos em uma reação molar, de um mol de metal para um, dois ou três (preferencialmente dois) moles de aminoácidos, que forma uma ligação covalente coordenada. Por definição, quelatos de metais aproximam-se dos proteinados, a diferença é que os quelatos devem ter um peso molecular máximo prédeterminado de 800 Daltons. Quando o tamanho do ligante aumenta, reduz a força da ligação entre as moléculas e pode diminuir a absorção); Metal Proteinado (resultante da quelação de um sal solúvel com aminoácidos ou proteínas parcialmente hidrolisadas. $\mathrm{O}$ produto final pode conter somente aminoácidos, dipeptídeos, tripeptídeos ou outros derivados de proteína. 
Geralmente, a mistura resultante possui uma ligação muito fraca, muitas vezes incapaz de resistir ao ambiente do trato gastrintestinal (constante de estabilidade muito baixa). Esses produtos são menos consistentes por definição e variam na produção e resultados de pesquisas). e; Metal Polissacarídeo (resultante da complexação de um sal solúvel com um polissacarídeo. Esse produto é uma matriz de mineral orgânico, sem ligações químicas entre o metal e o polissacarídeo. A matriz de polissacarídeo somente envolve o micromineral e promove alguma proteção física contra a degradação intestinal).

Lim et al. (2006) avaliaram a utilização de fontes orgânicas e inorgânicas de cobre. Os autores observaram que frangos suplementados com quelato $\mathrm{Cu}-$ metionina (100ppm) tiveram ganho de peso aos 35 dias de idade, 5,4\% maior do que os animais que receberam sulfato de cobre na ração. Observou-se também que o cobre proveniente do quelato $\mathrm{Cu}$-Met teve maior acúmulo no fígado, se comparado às outras fontes de cobre, o que indica que o quelato $\mathrm{Cu}$ Met é mais prontamente absorvido do que as outras formas de quelatos estudados.

Hudson et al. (2005) avaliaram a suplementação de $160 \mathrm{mg} / \mathrm{kg}$ de $\mathrm{Zn}$ de fontes inorgânicas (Sulfato de zinco), fontes orgânicas $(\mathrm{AA}+\mathrm{Zn})$ ou a combinação de ambas $\left(\mathrm{ZnSO}_{4}+\mathrm{AAZn}\right)$ para matrizes de frango de corte, após 20 semanas de idade, e seus efeitos subsequentes sobre o desempenho zootécnico dos pintos provenientes daquelas matrizes. Estes foram também alimentados com rações suplementadas de $140 \mathrm{mg} / \mathrm{kg}$ até aos 17 dias de idade. $\mathrm{O}$ uso de fontes inorgânicas e orgânicas em combinação $\left(\mathrm{ZnSO}_{4}, 100 \mathrm{mg} \mathrm{Zn} / \mathrm{kg}\right.$ + ZnAA, 40mg Zn/kg), para as matrizes, proporcionou maior peso corporal e melhor conversão alimentar aos pintos também alimentados com rações suplementadas pela combinação de $\mathrm{ZnSO}_{4}+\mathrm{ZnAA}$.

Yan \& Waldroup (2006) avaliaram a suplementação de manganês na forma orgânica e na forma inorgânica (óxido e sulfato de manganês) para frangos de corte Cobb 500. Não foram observados efeitos significativos sobre o desempenho zootécnico (peso corporal, consumo de ração, conversão alimentar e mortalidade) das aves. No entanto, foram observadas maiores concentrações de $\mathrm{Mn}$ nas tíbias das aves alimentadas com minerais orgânicos, cujos valores diferem de $15,81 \%$ e $53,89 \%$ para o sulfato de manganês e para o óxido de manganês, respectivamente. Já Arruda et al. (2004), quando avaliaram a substituição de selenito por selênio orgânico, constataram melhora no ganho de peso e na conversão alimentar de frangos de corte.

A suplementação de minerais orgânicos para as aves reflete-se basicamente na melhora do status do sistema imune e na resistência óssea com consequente redução de problemas de patas. Esses fatores refletem em melhor desempenho zootécnico das aves.

Diante da expectativa da proibição dos antibióticos promotores de crescimento nas rações de frangos de corte, várias pesquisas foram desenvolvidas com $\mathrm{o}$ objetivo de obter alternativas eficientes, de modo a enfatizar em especial o uso de probióticos, prebióticos e outras formas de reduzir os micro-organismos patógenos das aves.

Os prebióticos são ingredientes alimentares que não sofrem a ação de enzimas digestivas, mas que estimulam seletivamente o crescimento ou a atividade de bactérias benéficas no intestino. Esses carboidratos não digestíveis (como parede celular de plantas e leveduras) são classificados dessa forma por serem constituídos 
Rev. Bras. Saúde Prod. Anim., Salvador, v.13, n.3, p. 755-774 jul./set., 2012 http://www.rbspa.ufba.br ISSN 15199940

de complexos de oligomananoproteínas, principalmente de mananoligossacarídeos, que possuem a capacidade de ligar-se a fímbria das bactérias e inibir a colonização do aparelho digestivo.

Os prebióticos mais estudados como aditivos alimentares para as aves são os mananoligossacarídeos (MOS), os glucoligossacarideos (GOS) e os frutoligossacarídeos (FOS). $\mathrm{O}$ efeito positivo dos prebióticos (MOS) foi detectado por Rostagno et al. (2003b) quando utilizaram cama reutilizada, similar a um aviário comercial. Os frangos de corte, alimentados com rações compostas de antibiótico ou prebiótico, mostraram melhor ganho de peso e conversão alimentar que as aves da ração controle, sem promotor (Tabela 6).

Tabela 6. Efeito da utilização de prebiótico (MOS), sobre o desempenho de frangos de corte de 1 a 41 dias de idade

\begin{tabular}{lcc}
\hline Tratamento & Ganho de peso $(\mathrm{g})$ & Conversão alimentar \\
\hline Controle $(\mathrm{C})$ & $2398^{\mathrm{b}}$ & $1,915^{\mathrm{b}}$ \\
C + Avilamicina & $2480^{\mathrm{a}}$ & $1,859^{\mathrm{a}}$ \\
C + MOS I & $2487^{\mathrm{a}}$ & $1,859^{\mathrm{a}}$ \\
C + MOS II & $2485^{\mathrm{a}}$ & $1,860^{\mathrm{a}}$ \\
\hline
\end{tabular}

Adaptado de Rostagno et al. (2003b).

Em outro experimento realizado com pintos de 01 a 21 dias de idade, criados em cama reutilizada, Albino et al. (2006) avaliaram a adição de antibiótico e de prebióticos a base de MOS. Os autores verificaram não haver diferença sobre o ganho de peso entre os tratamentos formados por MOS e os demais tratamentos, apesar do tratamento por avilamicina ter proporcionado melhor resultado $(\mathrm{P}<0,05)$ - (Tabela 7$)$.

Tabela 7. Desempenho e viabilidade de pintos de corte machos de 1 a 21 dias submetidos a rações contendo prebióticos, antibiótico e suas combinações

\begin{tabular}{|c|c|c|c|c|}
\hline Tratamento & GP $(\mathrm{g})$ & CR (g) & $\mathrm{CA}$ & VIAB (\%) \\
\hline Ração Basal (RB) & $762,2^{b}$ & 1057,6 & 1,39 & 98,3 \\
\hline $\mathrm{RB}+$ Avilamicina $^{1}$ & $795,4^{\mathrm{a}}$ & 1092,2 & 1,37 & 97,8 \\
\hline $\mathrm{RB}+\operatorname{MOS} \mathrm{AT}^{2}$ & $769,4^{\mathrm{ab}}$ & 1072,3 & 1,39 & 99,4 \\
\hline $\mathrm{RB}+\operatorname{MOS~ST}{ }^{3}$ & $783,6^{\mathrm{ab}}$ & 1102,2 & 1,41 & 99,4 \\
\hline $\mathrm{RB}+\mathrm{MOS} \mathrm{AT}+$ Avilamicina & $785,6^{\mathrm{ab}}$ & 1091,8 & 1,39 & 97,8 \\
\hline $\mathrm{RB}+\mathrm{MOS} \mathrm{ST}+$ Avilamicina & $777,1^{\mathrm{ab}}$ & 1087,8 & 1,40 & 98,3 \\
\hline $\mathrm{CV}(\%)$ & 2,9 & 3,9 & 3,4 & 2,8 \\
\hline
\end{tabular}

Adaptado de Albino et al. (2006).

${ }^{\mathrm{ab}}$ Médias seguidas por uma mesma letra dentro da coluna não diferem entre si pelo teste de Student Newman Keuls a $5 \%$ de probabilidade.

${ }^{1}$ Surmax 100; ${ }^{2}$ Mananoligossacarídeo alta concentração; ${ }^{3}$ Mananoligossacarídeo standard. 
Existem resultados controversos na literatura sobre a efetividade dos prebióticos na nutrição de aves, assim como dos probióticos, discutidos mais a frente. No entanto, é extremamente importante salientar a necessidade de determinar a dosagem correta para cada tipo de aditivo e de considerar o desafio sanitário para a comprovação ou não da atuação destes, a fim de garantir a presença de organismos patogênicos como E. Coli e Salmonella.

A base do conceito da utilização dos probióticos é a manipulação da flora intestinal que influencia beneficamente a saúde do animal hospedeiro. Os principais micro-organismos utilizados como probióticos pertencem aos gêneros Lactobacillus, Bifidobacterium, Enterococcus, Streptococcus, Bacillus e leveduras.

O termo "exclusão competitiva", também denominado "Conceito de Nurmi", significa que a colonização intestinal por patógenos como Salmonella, E. coli $e$ Campylobacter spp pode ser prevenida mediante a administração oral de conteúdo intestinal de aves adultas normais aos pintinhos de um dia de idade (CORRIER et al., 1991). Para que a cultura de "exclusão competitiva" seja mais eficiente, é necessário que esta seja administrada rapidamente às aves, de preferência no incubatório.

Ao comparar o desempenho de frangos de corte Ross, machos, de 1 a 42 dias de idade alimentados com rações suplementadas com probiótico à base de Bacillus subtilis e com antibiótico, como promotor de crescimento, Lora Graña (2006) não observou diferenças nos parâmetros de desempenho entre os tratamentos compostos de probiótico e antibiótico, em nenhum dos períodos avaliados (inicial, crescimento e terminação). No entanto, maior valor de viabilidade foi encontrado no tratamento que continha $355 \mathrm{~g} / \mathrm{t}$ de probiótico, o que indica maior sobrevivência dos animais.

Já Flemming (2005), ao avaliar o desempenho de frangos de corte alimentados com dietas formadas de probióticos, prebióticos e ainda o efeito das associações desses produtos, concluiu que, na fase de 1 a 21 dias de idade, o probiótico acarretou um ganho de peso acumulado melhor do que o grupo controle, sem diferenciar estatisticamente dos outros tratamentos. Na fase de 1 a 42 dias de idade, não observou diferença entre os parâmetros de desempenho analisados (Tabela 8).

Tabela 8. Efeito da inclusão de aditivos na dieta de frangos de corte

\begin{tabular}{lcrrrrr}
\hline \multirow{2}{*}{ Tratamento } & \multicolumn{3}{c}{$1-21$ dias } & \multicolumn{3}{c}{$1-42$ dias } \\
\cline { 2 - 7 } & GP $(\mathrm{g})$ & CR $(\mathrm{g})$ & CA & GP $(\mathrm{g})$ & CR $(\mathrm{g})$ & CA \\
\hline Controle $^{\text {Antibiótico }}{ }^{1}$ & $770,8^{\mathrm{b}}$ & 1140,8 & 1,48 & $2510,5^{\mathrm{ab}}$ & 4643,5 & 1,85 \\
Probiótico $^{2}$ & $777,5^{\mathrm{ab}}$ & 1142,9 & 1,47 & $2494,9^{\mathrm{ab}}$ & 4590,7 & 1,84 \\
Simbiótico $^{3}$ & $814,2^{\mathrm{a}}$ & 1188,7 & 1,46 & $2553,8^{\mathrm{a}}$ & 4622,3 & 1,81 \\
\hline Ada $^{\mathrm{a}}$ & $797,7^{\mathrm{ab}}$ & 1180,6 & 1,48 & $2512,4^{\mathrm{ab}}$ & 4679,1 & 1,86 \\
\hline
\end{tabular}

Adaptado de Flemming (2005).

${ }^{1}$ Avilamicina $10 \mathrm{~g} / \mathrm{t} ;{ }^{2}$ Bacillus licheniformis e Bacillus subtilis $1 \mathrm{~kg} / \mathrm{t} ;{ }^{3}$ Probióticos $1 \mathrm{~kg} / \mathrm{t}+0,5 \mathrm{MOS} / \mathrm{t}$.

De certo, os probióticos e prebióticos possuem um futuro promissor na alimentação de frangos, sobretudo, com o avanço das restrições ao uso de antibióticos promotores de crescimento. Várias pesquisas demonstram resultados satisfatórios, principalmente, quanto à redução da mortalidade e por apresentar 
um custo/tonelada de ração similar ao do uso de antibióticos. Dessa forma, muitas empresas e granjas comerciais já têm feito uso desses aditivos como prática rotineira. Todavia, muitos questionamentos ainda merecem respostas diante da necessidade do melhor entendimento quanto às espécies e às concentrações dos microorganismos que devem ser utilizados.

Recentemente tem-se aumentado o interesse por essa classe de aditivos alimentares, especialmente, envolvidos com suínos e aves. Esse fato é reflexo da proibição de vários antibióticos na alimentação animal pela União Europeia.

Kamel (2000) comenta que os efeitos benéficos das plantas estão associados à constituição de seus princípios ativos e compostos secundários. $\mathrm{Se}$ for considerada a extensa variedade de plantas existentes, constituídas por inúmeras substâncias, o grande desafio na utilização de extratos vegetais, como alternativa ao uso de antimicrobianos, está na identificação e quantificação dos efeitos exercidos pelos diferentes componentes presentes nos óleos essenciais sobre o organismo animal.

Hoje em dia, existe a preconização de que os extratos herbais poderiam estimular as enzimas digestivas (KAMEL, 2000), aumentar a digestibilidade e absorção de nutrientes, possuírem atividade antibacteriana (UTIYAMA et al., 2006) e atividade antioxidante (BOTSOGLOU et al., 2002). Brugalli (2003) comenta que, dentre os possíveis mecanismos de ação dos óleos essenciais no organismo animal, aponta-se alterações na microflora intestinal, aumento na digestibilidade e absorção de nutrientes através do estímulo à atividade enzimática, melhoria da resposta imune, controle na produção de amônia e modificações morfo-histológicas no trato gastrointestinal.
As substâncias ativas das plantas medicinais podem ser classificadas de acordo com suas características físicas, químicas ou de atividade biológica. Os principais grupos existentes são os alcaloides (alcoóis, aldeídos, cetonas, éteres, ésteres e lactonas), glicosídeos, compostos fenólicos e polifenólicos (quinonas, flavonas, taninos e cumarinas), terpenóides (mono e sesquiterpenos e esteróides) saponinas, mucilagens, flavonóides e óleos essenciais (MARTINS et al., 2003). Tais substâncias geralmente não se encontram na planta em estado puro, mas sob a forma de complexos, cujos diferentes componentes se completam e reforçam sua ação sobre o organismo.

Bozkurt et al. (2009) constataram melhoras no desempenho e na conversão alimentar de frangos, no período de 1 a 21 dias de idade, com a inclusão de extrato de orégano, cuja performance foi semelhante ao de antibióticos testados no mesmo experimento.

Petrolli et al. (2011), ao trabalharem com diferentes extratos herbais para frangos de corte, verificaram que a utilização destes, nas dietas, podem substituir o uso de antibióticos, sem o comprometimento do desempenho e da mucosa intestinal de frangos de corte, no período de 1 a 40 dias de idade (Tabela 9).

Fukayama et al. (2005) observaram que não houve diferença significativa entre o uso de extrato de orégano ou antibiótico na dieta de frangos de corte, o que comprova a eficácia do extrato em substituição ao antibiótico (Tabela 10).

Ao considerar os trabalhos citados e vários outros, considera-se os aditivos fitogênicos como importantes substitutos aos antibióticos promotores de crescimento, que promovem efeitos benéficos, sem prejudicar o desempenho de frangos de corte. 
Rev. Bras. Saúde Prod. Anim., Salvador, v.13, n.3, p.755-774 jul./set., 2012 http://www.rbspa.ufba.br ISSN 15199940

Tabela 9. Desempenho de frangos de corte de 1 aos 40 dias

\begin{tabular}{lcccc}
\hline Tratamentos & PV $(\mathrm{g})$ & GP $(\mathrm{g})$ & CR $(\mathrm{g})$ & CA \\
\hline CP + 10ppm Av. & $2527,8^{\mathrm{a}}$ & $2482,1^{\mathrm{a}}$ & $4138,7^{\mathrm{a}}$ & $1,67^{\mathrm{a}}$ \\
Controle Positivo (CP) & $2500,5^{\mathrm{a}}$ & $2456,7^{\mathrm{a}}$ & $4113,7^{\mathrm{a}}$ & $1,67^{\mathrm{a}}$ \\
Controle Negativo (CN) $_{\text {CN + Comp. Fitoterápico* }}$ & $2395,6^{\mathrm{b}}$ & $2351,0^{\mathrm{b}}$ & $4026,8^{\mathrm{a}}$ & $1,71^{\mathrm{b}}$ \\
CN + 75ppm Ex. Alho & $2442,1^{\mathrm{ab}}$ & $2397,3^{\mathrm{ab}}$ & $4057,9^{\mathrm{a}}$ & $1,69^{\mathrm{ab}}$ \\
CN + 150 ppm Ex. Alho & $2442,9^{\mathrm{ab}}$ & $2399,1^{\mathrm{ab}}$ & $3995,7^{\mathrm{a}}$ & $1,66^{\mathrm{a}}$ \\
\hline CV $(\%)$ & $2521,9^{\mathrm{a}}$ & $2469,6^{\mathrm{a}}$ & $4163,1^{\mathrm{a}}$ & $1,69^{\mathrm{ab}}$ \\
\hline
\end{tabular}

Adaptado de Petrolli et al. (2011).

*100ppm do complexo fitoterápico (5ppm carvacrol + 3ppm cinamaldeído + 2ppm capsaicína).

${ }^{a, b}$ Médias seguidas de letras diferentes na mesma coluna indicam diferença significativa $(\mathrm{P}<0,05)$ pelo teste SNK.

Tabela 10. Ganho de peso (GP), Consumo de ração (CR) e Conversão alimentar (CA) de frangos de corte alimentados com rações contendo extrato de orégano

\begin{tabular}{lcccccc}
\hline \multirow{2}{*}{ Tratamento } & \multicolumn{3}{c}{$1-21$ dias } & \multicolumn{3}{c}{$1-42$ dias } \\
\cline { 2 - 7 } & GP $(\mathrm{g})$ & $\mathrm{CR}(\mathrm{g})$ & $\mathrm{CA}$ & $\mathrm{GP}(\mathrm{g})$ & $\mathrm{CR}(\mathrm{g})$ & $\mathrm{CA}$ \\
\hline $\mathrm{CN}^{1}$ & 653 & 1128 & 1,73 & 2510 & 4357 & 1,74 \\
$\mathrm{CP}^{2}$ & 672 & 1134 & 1,69 & 2567 & 4354 & 1,71 \\
Orégano 0,025\% & 687 & 1142 & 1,66 & 2631 & 4372 & 1,67 \\
Orégano 0,050\% & 687 & 1137 & 1,66 & 2444 & 4444 & 1,84 \\
Orégano 0,075\% & 677 & 1121 & 1,66 & 2637 & 4338 & 1,65 \\
Orégano 0,100\% & 683 & 1144 & 1,68 & 2597 & 4333 & 1,67 \\
\hline
\end{tabular}

Adaptado de Fukayama et al. (2010).

${ }^{1}$ Controle negativo: ração basal; ${ }^{2}$ ontrole positivo: ração basal + antibiótico.

Atualmente, reduzir o custo de produção e melhorar o rendimento industrial são os principais desafios da avicultura mundial. Nesse sentido, o uso de enzimas exógenas em rações para aves tem sido muito difundido para melhorar a digestibilidade dos nutrientes e a energia das rações.

Alguns autores sugerem que as enzimas exógenas devem ser utilizadas somente em situações nas quais os animais não sejam capazes de sintetizá-las. Entretanto, Wenk (2002) relata que a suplementação de enzimas exógenas pode melhorar a eficiência das enzimas endógenas. É o caso da amilase, cujo substrato é o amido, e é suplementada às rações no intuito de melhorar a eficiência da degradação do amido. Esse efeito pode ser de grande importância especialmente em aves jovens, pois, de acordo com Noy \& Sklan (1995), em pintos jovens, alimentados com rações à base de milho e farelo de soja, a digestibilidade ileal é baixa, tanto do amido, como da gordura.

Esse interesse na utilização de enzimas em rações se deve aos custos cada vez maiores das matérias primas tradicionais e à busca por ingredientes alternativos, como a cevada, aveia, arroz e trigo, entre outros. As enzimas também são tratadas como uma forma de reduzir a contaminação ambiental por nutrientes 
das excretas, tais como o fósforo, o nitrogênio, o cobre e o zinco.

Com a proibição do fornecimento da cama de frango para bovinos, a principal utilização dos dejetos avícolas se faz com fertilizantes na agricultura, o que pode levar à contaminação dos lençóis freáticos, pela lixiviação de minerais presentes nas excretas. Uma maneira de se reduzir esse impacto ambiental é através da manipulação da dieta, ao se fornecer dietas melhor balanceadas e utilizar aditivos e ingredientes de alta biodisponibilidade com o intuito de melhorar a eficiência de utilização pelos animais dos nutrientes contidos nos alimentos

Com essa finalidade, o uso de enzimas exógenas tem sido alvo de vários estudos, dos quais se destaca a utilização da fitase, que por sua vez, possibilita a liberação do fósforo fítico e de outros nutrientes. Isso pode reduzir a suplementação com fósforo inorgânico e o custo, bem como melhorar a utilização do fósforo presente nos alimentos, além de reduzir o fósforo excretado. Laurentiz et al.
(2007), ao avaliarem níveis reduzidos de fósforo disponível em cada fase de criação e a suplementação da enzima fitase $(100 \mathrm{~g} / \mathrm{t})$ em dietas de frangos de corte, observaram que quando se reduziu o fósforo disponível em todas as fases de criação (inicial, crescimento e final), ocorreu redução nos teores de nitrogênio, de fósforo, de zinco, de manganês e de cobre presentes na cama dos frangos.

A suplementação de enzimas, entre outros, possibilita melhorar a disponibilidade de nutrientes; eliminar fatores antinutricionais; aumentar o valor nutricional de ingredientes; utilizar alimentos de menor qualidade nutricional e melhorar a formulação das rações uma vez que melhora a qualidade nutricional dos ingredientes e reduz erros na estimativa do conteúdo em nutrientes.

Existem três grupos de enzimas no mercado: as utilizadas em dietas de baixa viscosidade, as usadas em dietas de alta viscosidade e; as destinadas a degradar o ácido fítico dos alimentos vegetais (Tabela 11).

Tabela 11. Resumo de enzimas utilizadas na ração de aves

\begin{tabular}{|c|c|c|}
\hline Enzima & Substrato & Efeitos \\
\hline Xilanase & Arabinoxilanos & Redução da viscosidade da ração \\
\hline Glucanase & $\beta$-glucanos & $\begin{array}{l}\text { Redução da viscosidade da ração e menor } \\
\text { umidade na cama }\end{array}$ \\
\hline Pectinase & Pectinas & Redução da viscosidade da ração \\
\hline Celulase & Celulose & $\begin{array}{l}\text { Degradação de celulose e liberação de } \\
\text { nutrientes }\end{array}$ \\
\hline Protease & Proteínas & $\begin{array}{l}\text { Suplementação das enzimas endógenas; } \\
\text { degradação mais eficiente de proteínas }\end{array}$ \\
\hline Amilase & Amido & $\begin{array}{l}\text { Suplementação das enzimas endógenas; } \\
\text { degradação mais eficiente do amido }\end{array}$ \\
\hline Fitase & Ácido fítico & $\begin{array}{l}\text { Melhora a utilização do fósforo dos } \\
\text { vegetais. Degradação do ácido fítico }\end{array}$ \\
\hline Galactosidase & Galactosídios & Remoção de galactosídeos \\
\hline Lipase & Lipídios e ác. graxos & $\begin{array}{l}\text { Melhora a utilização de gorduras animais e } \\
\text { vegetais }\end{array}$ \\
\hline
\end{tabular}

Adaptado de Cleóphas et al. (1995). 
Duas estratégias podem ser aplicadas na utilização das enzimas. A primeira, mais simples e de aplicação prática para aves jovens ( 1 a 21 dias de idade), denominada adição on top, de uma formulação que consiste em adicionar o complexo enzimático a uma formulação já existente, que supostamente atenda às exigências nutricionais, com o objetivo de melhorar a eficiência, o desempenho e o custo do frango. A segunda opção é modificar a formulação alimentar, de modo a promover a redução nos níveis nutricionais, o que normalmente resulta em menor desempenho dos frangos. Entretanto, a adição de enzimas exógenas melhora o aproveitamento nutricional do alimento e provoca um desempenho normal dos animais. Com isso, a produção é a mesma, porém os custos alimentares são reduzidos, mesmo quando o custo da enzima for incluído.

No intuito de avaliarem o efeito da fitase em rações baseadas em milho e farelo de soja, com duas diferentes relações Ca:P (normal e baixo), sobre o desempenho e a digestibilidade de nutrientes em frangos de corte, no período de 19 a 24 dias de idade, Tejedor et al. (2001) verificaram efeito positivo da adição da fitase sobre os coeficientes de digestibilidade aparente ileal do cálcio (aumento de 5,2\% no $\mathrm{CDCa}$ ) e do fósforo (aumento de 3,9\% no coeficiente). Meng \& Slominski (2005) e Zanella et al. (2004) encontraram também melhora na digestibilidade do amido (a primeira fonte de energia) com a suplementação de algumas enzimas.

Viana et al. (2009), ao testarem a suplementação de fitase para poedeiras, observaram que as aves alimentadas com a dieta controle apresentaram maiores valores de EMA e de EMAn, quando comparadas com aquelas que receberam dietas do controle negativo. No entanto, a suplementação $100 \mathrm{~g} / \mathrm{t}$ de uma fitase proporcionou resultados de EMAn semelhantes aos encontrados no controle positivo.

Pessôa (2010), em estudo do efeito da suplementação de um complexo enzimático sobre o desempenho de frangos de corte, sobre os valores de energia metabolizável da dieta e sobre os balanços de fósforo e nitrogênio, encontrou resultados satisfatórios com a inclusão do complexo. Quanto ao desempenho, observou que a adição do complexo enzimático melhorou $\mathrm{o}$ desempenho dos animais em todas as fases de criação, seu efeito mais pronunciado se deu no ganho de peso $(+3,92 \%)$ e sobre a conversão alimentar $(-2,74 \%)$ dos animais do período de 1 a 42 dias. Quanto aos outros parâmetros, a adição do complexo enzimático, composto de protease, amilase, celulase, pectinase, xilanase, $\beta$-glucanase e fitase, proporcionou uma melhora de $2,05 \%$ e de 2,02\% no aproveitamento da EMA e da EMAn, respectivamente. Também foi eficiente quanto ao balanço de fósforo, de modo a aumentar em 10,3\% a retenção desse mineral devido à presença da enzima fitase. Quanto ao nitrogênio, o uso do complexo enzimático proporcionou uma redução de $3,30 \%$ na excreção e um aumento de 5,30\% na retenção desse mineral.

De forma geral, as enzimas facilitam a digestão e melhoram a saúde intestinal dos animais. Os benefícios podem ser observados no ganho de peso, rendimento de carcaça e ainda na possibilidade de se reduzir o uso de ingredientes caros para a formulação de ração.

A atualização constante do profissional permitirá acompanhar as mudanças tecnológicas na área de nutrição/produção de frangos de corte, assim como poder gerar e adaptar novas tecnologias as condições brasileiras. 
Rev. Bras. Saúde Prod. Anim., Salvador, v.13, n.3, p. $755-774$ jul./set., 2012 http://www.rbspa.ufba.br ISSN 15199940

As diferentes estratégias nutricionais buscam melhorar o aproveitamento dos nutrientes e aumentar a produtividade dos animais, bem como reduzir a excreção de nutrientes pelos animais, pois a preocupação com a preservação do meio ambiente deve ser preocupação constante dos nutricionistas. Além disso, existe a vantagem de que algumas delas ainda reduzem os custos de produção.

\section{REFERÊNCIAS}

ASSOCIATION OF AMERICAN FEED CONTROL OFFICIALS - AAFCO.

Official publication. Champaign, 1999. P.143.

ARRUDA, J.S.; RUTZ, F.; PAN, E. A. Influence os replacing dietary inorganic witch organic selenium on peformance of broilers. In: ANNUAL SYMPOSIUM ON BIOTECHNOLOGY IN THE FEED INDUSTRY, 20., 2004, Lexington. Proceedings... Lexington: 2004. p.13

AVISITE. O Portal e Revista de Apicultura. 2011. Disponível em: <http://www.avisite.com.br>. Acesso em: 14 fev. 2011.

BORGES, S.A.; DAHLKE, F.; LAURENTIZ, A.C. et al. Impacto da formulação com conceito de proteína ideal em dietas com soja integral e ingredientes alternativos para frangos de corte. Revista Brasileira de Ciência Avícola, v.5, p.28, 2003.

BOTSOGLOU, N.A.; FLOROUPANERI, P.; CHRISTAKI, E.; FLETOURIS, D.J.; SPAIS, A.B. Effect of dietary oregano essential oil on performance of chickens and on ironinduced lipid oxidation of breast, thigh and abdominal fat tissues. British
Poultry Science, v.43, n.2, p.223-230. 2002.

BOZKURT M.; KÜCÜKYILMAZ, K.; CATLI, A.U.; CINAR, M. Effect of dietary mannan oligosaccharide with or without oregano essential oil and hop extract supplementation on the performance and slaughter characteristics of male broilers. South African Journal of Animal Science, v.39, n.3, p.223-232. 2009.

BRUGALLI, I. Alimentação alternativa: a utilização de fitoterápicos ou nutracêuticos como moduladores da imunidade e desempenho animal. In: SIMPÓSIO SOBRE MANEJO E NUTRIÇÃO DE AVES E SUÍNOS, 2003, Campinas. Anais... Campinas: Colégio Brasileiro de Nutrição Animal, 2003. p.167-182.

BURNHAM, M.R.; PEEBLES, E.D.; GARDNER, C.W.; BRAKE, J.; BRUZUAL, J.J.; GERARD, P.D. Effects of incubator humidity and hen age on yolk composition in broiler hatching eggs from young breeders. Poultry Science, v.80, n.10, p.14441450, 2001.

BUTERI, C.B. Efeitos de diferentes planos nutricionais sobre a composição e o desempenho produtivo e econômico de frangos de corte. 2003. 252p.Tese (Doutorado em Zootecnia) - Universidade Federal de Viçosa, Viçosa, MG.

BUTERI, C.B.; TAVERNARI, F.C.; LELIS, G.R.; ROSTAGNO, H.S.; ALBINO, L.F.T. Effects of different nutritional plans on broiler performance. Revista Brasileira de Ciência Avícola, v.11, n.4, p.225-234, 2009. 
Rev. Bras. Saúde Prod. Anim., Salvador, v.13, n.3, p. $755-774$ jul./set., 2012 http://www.rbspa.ufba.br ISSN 15199940

CAMPOS, A.M.A. Nutrição

embrionária in-ovo. 2007. Dissertação

(Mestrado em Zootecnia) -

Universidade Federal de Viçosa,

Viçosa, MG.

CAO, J.; HENRY, P.R.; GUO, R.;

HOLWERDA, R.A.; TOTH, J.P.;

LITTELL, R.C.; MILES, R.D.;

AMMERMAN, C.B. Chemical

characteristics and relative

bioavailability of supplemental organic

zinc sources for poultry and ruminant.

Journal of Animal Science, v.78, n.8, p.2039-2054, 2000.

CAUWENBERGHE, S.V.;

BURNHAM, D. New developments in amino acid protein nutrition of poultry, as related to optimal performance and reduced nitrogen excretion. In: EUROPEAN SYMPOSIUM OF POULTRY NUTRITION, 2001, Blankenberge. Anais... Blankenberge, 2001. p.234.

CLEÓPHAS, G.M.L.; VAN HARTNGSVELDT, W.; SOMERS, W.A.C.; VAN der LUGT, J.P.K.

Enzymes can play an important role in poultry nutrition. World Poultry, v.11, n.4, p.12-15, 1995.

CORRIER, D.E.; HARGIS, B.; HINTON JR., A.; LINDSEY, D.; CALDWELL, D.; MANNING, J.; DELOACH, J. Effect of anaerobic cecal microflora and dietary lactose on colonization resistance of layer chickens to invasive Salmonella enteritidis.

Avian Diseases, v.35, p.337-343, 1991.

EMMERT, J.L.; BAKER, D.H. Use of the ideal protein concept for precision formulation of amino acid levels in broiler diets. Journal of Applied Poultry Research, v.6, p.462-470, 1997.
ALBINO, L.F.T.; FERES, F.A.; DIONIZIO, M.A.; ROSTAGNO, H.S.; VARGAS JÚNIOR, J.G.; CARVALHO, D.C.O.; GOMES, P.C.; COSTA, P.H.R. Uso de prebióticos à base de mananoligossacarídeo em rações para frangos de corte. Revista Brsileira de Zootecnia, v.35, n.3, p.742-749, 2006.

FERKET, P.R.; VAN HEUGTEN, E.; VAN KEMPEN, T.A.T.G.; ANGEL, R. Nutritional strategies to reduce environmental emissions from nonruminants. Journal of Animal

Science, v.80, p.168-182, 2002. . Suppl.2.

FLEMMING, J.S. Utilização de leveduras, probióticos e mananoligossacarídeos (MOS) na alimentação de frangos de corte. 2005. 111p. Tese (Doutorado em Tecnologia de Alimentos) - Universidade Federal do Paraná, Curitiba, PR.

FOYE, O.; FERKET, P.; UNI, Z. The effects of in ovo feeding of beta-hydroxybetamethylbutyrate (HMB) and arginine on jejunal expression and function in turkeys. Poultry Science, v.84, n.1, p.41, 2005.

FUKAYAMA, E.H.; BERTECHINI, A.G.; GERALDO, A.; KATO, R.K.; MURGAS, L.D.S. Extrato de orégano como aditivo em rações para frangos de corte. Revista Brasileira de Zootecnia, v.34, n.6, p.2316-2326, 2005. Supl.

GERAERT, P.A.; MERCIER, Y.; JAKOB, S. Utilization of the factorial model to determine the nutritional requirement of poultry and swine: practical aspects. In: SIMPÓSIO INTERNACIONAL SOBRE EXIGÊNCIAS NUTRICIONAIS DE AVES E SUÍNOS, 2., 2005, Viçosa. Anais... Viçosa, MG, 2005. p.293-292. 
Rev. Bras. Saúde Prod. Anim., Salvador, v.13, n.3, p. $755-774$ jul./set., 2012 http://www.rbspa.ufba.br ISSN 15199940

HUDSON, B.P.; DOZIER III, W.A.; WILSON, J.L. Broiler live performance response to dietary zinc source and the influence of zinc supplementation in broiler breeder diets. Animal Feed Science and Technology, v.118, Issues 3-4, p.329-335, 2005.

KAMEL, C. A novel look at a classic approach of plant extracts. Feed Mix, v.18, n.6, p.19-24, 2000.

KIEFER, C. Minerais quelatados na nutrição de aves e suínos. Revista Eletrônica Nutritime, v.2, n.3, p.206220. 2005.

LADGARY, L.; CAHANER, A.; KEDAR, O.; UNI, Z. Yolk sac nutrient composition and fat uptake in late-term embryos in eggs from young and old broiler breeder hens. Poultry Science, v.89, n.11, p.2441-2452. 2010.

LANA, G.R.Q.; SILVA JUNIOR, R.G.C.; VALERIO, S.R.; LANA, A.M.Q.; CORDEIRO, E.C.G.B. Efeito da densidade e de programas de alimentação sobre o desempenho de frangos de corte.

Revista Brasileira de Zootecnia, v.30, n.4, p.1258-1265. 2001.

LAURENTIZ, A.C.; JUNQUEIRA, O.M.; FILARDI, R.S.; ASSUENA, V.; CASARTELLI, E.M.; COSTA, R. Efeito da adição da enzima fitase em rações para frangos de corte com redução dos níveis de fósforo nas diferentes fases de criação. Ciência Animal Brasileira, v.8, n.2, p.207-216, 2007.

LIM, H.S.; PAIK, I.K.; SOHN, T.I.; KIM, W.Y. Effects of supplementary copper chelates in the form of methionine, chitosan and yeast on the performance of broilers. AsianAustralasian Journal of Animal Sciences, v.19, n.9, p.1322-1327, 2006.
LORA GRAÑA, A. Uso de probiótico em rações de frangos de corte. 2006. 31p. Dissertação (Mestrado em Zootecnia) - Universidade Federal de Viçosa, Viçosa, MG.

MARTINS, E.R.; CASTRO, D.M.; CASTELLANI, D.C.; DIAS, J.E. Plantas medicinais. Viçosa, MG: Universidade Federal de Viçosa, 2003. 220p.

MENG, X.; SLOMINSKI, A. Nutritive value of corn, soybean meal, canola meal, and peas for broiler chickens as affected by a multicarbohydrase preparation of cell wall degrading enzymes. Poultry Science, v.84, p.1242-1251, 2005.

NERY, L.R.; ALBINO, L.F.T.; ROSTAGNO, H.S., LORA GRAÑA, A.; BORSATTO, C.G.; BRITO, C.O. Efeito da utilização de dieta pré-alojamento sobre o desempenho de frangos de corte. Revista Brasileira de Ciência Avícola, v.88, p.120, 2006. Supl.

NOY, Y.; SKLAN, D. Decreasing weight loss in the hacthery by feeding chickens and poults in hatching trays. Journal Applied Poultry Research, v.9, p.142$148,2000$.

NOY, I.; SKLAN, D. Digestion and absorption in the young chick. Poultry Science, v.74, p.366-373, 1995.

NOY, Y.; SKLAN, D. Metabolic Responses to Early Nutrition. Journal Applied Poultry Research, v.7, p.437451, 1998.

PESSÔA, G.B.S. Avaliação de complexo enzimático em dietas de frangos de corte. 2010. 65p Dissertação (Mestrado em Zootecnia) - Universidade Federal de Viçosa, Viçosa, MG. 
Rev. Bras. Saúde Prod. Anim., Salvador, v.13, n.3, p. $755-774$ jul./set., 2012 http://www.rbspa.ufba.br ISSN 15199940

PETROLLI, T.G.; ALBINO, L.F.T.; ROSTAGNO, H.S. Extratos herbais em dietas de frangos de corte. Revista AgroMinas, v.1, n.9, p.26-28. 2011.

POPE, H.R.; LOUPE, L.N.; TOWNSEND, J.A.; EMMERT, J.L. Growth performance of broilers using a phase-feeding approach with diets switched every other day from fortytwo to sixty-three days of age. Poultry Science, v.81, p.466-471, 2002.

ROSTAGNO, H.S. ALBINO, L.F.T.; DONZELE, J.L.; GOMES, P.C.; OLIVEIRA, R.F.; LOPES, D.C.; FERREIRA, A.S.; BARRETO, S.L.T. Tabelas brasileiras para aves $\mathrm{e}$ suínos: composição de alimentos e exigências nutricionais. 2.ed. Viçosa, MG: Universidade Federal de Viçosa. 186p. 2005.

ROSTAGNO, H.S. ALBINO, L.F.T.; DONZELE, J.L.; GOMES, P.C.; OLIVEIRA, R.F.; LOPES, D.C.; FERREIRA, A.S.; BARRETO, S.L.T.; EUCLIDES, R.F. Tabelas brasileiras para aves e suínos: composição de alimentos e exigências nutricionais. 3.ed. Viçosa, MG: Universidade Federal de Viçosa. 252p. 2011.

ROSTAGNO, H.S.; ALBINO, L.F.T.; TOLEDO, R.S.; CARVALHO, D.C.O.; OLIVEIRA, J.E.; DIONIZIO, M.A. Efeito de prebiótico (MOS) em rações de frangos de corte contendo milhos de diferente qualidade nutricional. Revista Brasileira de Ciência Avícola, v.5, p.52, 2003b. Supl.

ROSTAGNO, H.S.; BERNAL, L.E.P.; TOLEDO, R.S. Dietas vegetais de pollos de engorde de alta produtividade. In: CONGRESSO LATINOAMERICANO DE AVICULTURA, 18, 2003, Santa Cruz, Bolívia. Anais... Santa Cruz, Bolívia, 2003a. p.397-410.
ROSTAGNO, H.S.; VARGAS

JUNIOR, J.G.; ALBINO, L.F.T. et al.

Níveis de proteína e de aminoácidos nas rações de pintos de corte. Revista Brasileira de Ciência Avícola, v.4, p.49, 2002a. Supl.

ROSTAGNO, H.S.; VARGAS JUNIOR, J.G.; ALBINO, L.F.T. et al. Níveis de proteína e de aminoácidos nas rações de frangos de corte de 22 a 40 dias de idade. Revista Brasileira de Ciência Avícola, v.4, p.53, 2002 b. Supl.

SHIROMA, N.N.; ZANETTI, M.A.; FARIA, D.E.; ALBUQUERQUE, R.; ANZAI, N.H. Efeito de programas de alimentação sobre o desempenho de frangos de corte machos durante $o$ inverno. CONFERENCIA APINCO DE CIENCIA E TECNOLOGIA AVICOLAS, 1996, Curitiba. Anais... Curitiba 1996.p.28.

TAKO, E.; FERKET, P.R.; UNI, Z. Effects of in ovo feeding of carbohydrates and betahydroxy-betamethylbutyrate on the development of chicken intestine. Poultry Science, v.83, p.2023-2028, 2004.

TEJEDOR, A.A.; ALBINO, L.F.T.; ROSTAGNO, H.S. Efeito da adição da enzima fitase sobre o desempenho e a digestibilidade ileal de nutrientes.

Revista Brasileira de Zootecnia, v.30, n.3, p.802-808, 2001.

UNI, Z.; FERKET, P.R.; TAKO, E.; KEDAR, O. In ovo feeding improves energy status of late-term chicken embryos. Poultry Science, v.84, p.764770, 2005.

UTIYAMA, C.E.; OETTING, L.L.; GIANI, P.A.; RUIZ, U.S.; MIYADA, V.S. Efeitos de antimicrobianos, prebióticos, probióticos e extratos 
Rev. Bras. Saúde Prod. Anim., Salvador, v.13, n.3, p. $755-774$ jul./set., 2012 http://www.rbspa.ufba.br ISSN 15199940

vegetais sobre a microbiota intestinal, a freqüência de diarréia e o desempenho de leitões recém-desmamados. Revista Brasileira de Zootecnia, v.35, n.6, p.2359-2367, 2006.

VIANA, M.T.S.; ALBINO, L.F.T.; ROSTAGNO, H.S.; SILVA, E.A.; MESSIAS, R.K.G.; PEREIRA, J.P.L. Efeito do uso de enzimas sobre o desempenho e metabolismo de poedeiras. Revista Brasileira de Zootecnia, v.38, n.6, p.1068-1073. 2009.

WARREN, W.A.; EMMERT, J.L. Efficacy of phase-feeding in supporting growth performance of broiler chicks during the starter and finisher phases. Poultry Science, v.79, p.764-770. 2000.
WENK, C. Growth promoter alternatives after the ban of antibiotics. Hồ Chí Minh, Vietnan: Department of Veterinary, 2002.

YAN, F; WALDROUP, P.W. Evaluation of MINTREX ${ }^{\circledR}$ Manganese as a source of manganese for young broilers. International Journal of Poultry Science, v.5, p.703-708. 2006.

ZANELLA, I.; SAKOMURA, N.K.; ROSA, A.P.; FIGUEIREDO, A.N.; MAGON, L. Efeito da suplementação de enzimas sobre a digestibilidade de dietas à base de milho e de sojas processadas para frangos de corte. Ars Veterinaria, v.20, n.2, p.144-150, 2004.

Data de recebimento: 10/11/211

Data de aprovação: 15/06/2012 